\title{
TEMAS DA PEDAGOGIA DO ESPORTE, EDUCAÇÃO ESPORTIVA E COMPETIÇÕES
}

Renato Sampaio Sadi

\section{Resumo}

Este artigo discute de forma geral e específica os principais temas da pedagogia do esporte. A abordagem metodológica da educação esportiva em jogos e competições é apresentada sob a forma de uma proposta.

\section{Palavras-Chave:}

Esporte; Pedagogia; Competição.

\section{FEAR OF THE SPORT PEDAGOGY, SPORTING EDUCATION AND COMPETITIONS}

Renato Sampaio Sadi

\section{Abstract}

This article argues of general and specific form the main subjects of sport pedagogy. The methodological approach of the sport education in games and competitions is presented under the form of a proposal.

\section{Key-Words}

Sport; Pedagogy; Competition. 


\section{INTRODUÇÃO}

O debate da pedagogia do esporte como uma subárea da educação física tem sido desenvolvido a partir dos dois principais eixos da área: aquele que se fundamenta nas ciências da saúde e aquele baseado nas referências sócio-culturais. Nos últimos anos verificamos que o tema da pedagogia do esporte esteve presente em vários fóruns, revistas acadêmicas e na formação inicial e continuada.

Entretanto, se a expansão do debate da pedagogia do esporte é uma realidade inquestionável, o mesmo não se pode dizer do conteúdo (qualidade) deste debate, ou seja, nesta lógica, ainda estaríamos vivendo um tempo de especulações teórico-práticas, reproduzindo dominantemente, intenções e desejos de mudança em detrimento de projetos efetivos para esta subárea, a pedagogia do esporte.

Ao revisar os conceitos de jogo e esporte relacionando-os com uma perspectiva de educação esportiva, entendemos que é importante apontar uma nova prática problematizando um projeto de pedagogia do esporte. Balizamos esta discussão com os determinantes de uma teoria americana de educação esportiva, mais especificamente, as contribuições de MITCHELL, OSLIN; GRIFFIN (2003).

O ensino, a preparação, a repetição como fixação de aprendizagem e o treinamento de formas corporais relacionadas ao fazer esportivo estão presentes nas aulas de educação física e esporte como estratégia educativa em busca de qualidade. Isso implica no tratamento de uma dinâmica curricular que normalmente extrapola as séries de exercícios, jogos e atividades promovidas pelo ensino tradicional.

Quando o saber esportivo é ensinado de forma fragmentada, isto é, as partes técnicas são apresentadas fora do contexto do jogo, o processo de aprendizagem global, constituído por uma série de mecanismos de interação, fica prejudicado. Ao não se observar as totalidades implícitas na totalidade maior que é o próprio esporte, a técnica isolada dos chamados fundamentos esportivos corrobora a compreensão do esporte como jogo para poucos. Dessa forma a qualidade está na técnica como modelo e o modelo da qualidade é a perfeição ou estética hegemônica do gesto, que acaba enquadrando a técnica como fragmento e recorte isolado do fazer esportivo humano. Nesse sentido despreza-se e descarta-se a compreensão de totalidade. Na verdade esse movimento é próprio da pós-modernidade e sua ruptura com a totalidade das meta narrativas educacionais. A consciência e inteligência social são descentradas. Há um giro a favor do sujeito egoísta, aquele que detém posses e um ataque às formulações filosóficas e gerais do ser social, do ser coletivo, das meta narrativas (SILVA, 2002) Esta construção sociológica também está presente na educação esportiva de crianças e jovens e constitui uma referência teórica importante 
para o enquadramento da pedagogia do esporte. Por outro lado, no campo da política, a incerteza que se imbrica na ausência (ou fragilidade) de projeto, impõe, dentro do cenário da pós-modernidade, uma resposta afirmativa, ou seja, a necessidade de reconstruir as esperanças. (FREITAS, 2005).

No campo da cultura do esporte, o Brasil, como outros países, herdou características do tecnicismo, isto é, elementos do processo histórico engendrado no binômio conhecido como fordismo/taylorismo. As variações educacionais foram pautadas pelo ensino tradicional de esportes que reforçaram as pautas militares. Tal matriz se ramificou (e continua a se ramificar) nos simbolismos da reprodução motora da criança e nos próprios gestos técnicos de iniciação esportiva.

Um dos aspectos interessantes no debate acadêmico da Educação física foi a questão do objeto de estudo. (DAOLIO, 2004) Entre os conceitos de cultura do movimento, cultura corporal e motricidade humana, preferimos o conceito de cultura corporal/esportiva por entender que o esporte como jogo integra a totalidade desta cultura (SADI, 2005)

Compreendendo que o esporte pode funcionar como alavanca democrática, recuperamos os principais temas arrolados no debate nacional da Educação física indicando articulações com as possibilidades concretas de atividades de esporte escolar. Os principais aspectos podem ser resumidos em:

- Oportunidade para o desenvolvimento da autonomia dos sujeitos nas aulas de educação física, educação esportiva e desenvolvimento esportivo;

- Oportunidade de aprender e praticar a resolução de problemas dentro e, a partir dos jogos, articulando recursos estratégicos e inteligentes do fazer esportivo.

- Criatividade e crítica como arma do professor. Qualificar o profissional com um tipo de "ferramenta" que o transformaria em "arquiteto de jogos", para assim contribuir com idéias que criem possibilidades de aprendizagem significativa, melhora da performance e desenvolvimento de criatividade nos alunos;

- Convívio social e ético dos alunos. A educação esportiva desenvolvida dentro de ambientes criativos deve ter como meta o processo de cidadania esportiva.

Precisamos, nesse sentido, verificar a prática da pedagogia do esporte, observando os graus de qualidade existentes para auxiliar na busca por uma nova qualidade. Pesquisar o esporte tendo como eixo, de um lado, a atual pedagogia desenvolvida e, de outro, uma nova pedagogia criativa, requer focar os processos e resultados do ensino, visando extrair elementos de superação da realidade. Esta engenharia 
pode ser possível para a pedagogia do esporte, desde que o desafio estratégico e metodológico da qualidade educacional seja superado. Historicamente resgatamos a prática pedagógica a partir dos mini jogos, reelaborando o tema da autonomia do aluno-jogador (ALBERTI; ROTHENBERG, 1984; DIECKERT, 1984; DUCKER, 2004; FREIRE, 1992 e 1999).

Apoiados nas determinações do esporte escolar e questionando suas contradições e limites, entendemos que os processos de reformulação e oxigenação para a busca de uma nova qualidade em esportes são constituídos por uma totalidade teórico-prática. Parece-nos que o fato de não compreender esta engrenagem que está implícita tanto nos gestos esportivos quanto nas táticas e comportamentos em situação de jogo leva (e continua levando) os professores à manutenção de uma prática profissional rotineira e burocrática composta por "exercícios de fundamentos técnicos e/ou táticos".

Embora as tentativas de aplicação em jogos e a criatividade desenvolvida tenham sido conduzidas como alternativa do fazer pedagógico, a dominância da concepção tradicional do esporte escolar repousa sobre a qualidade técnica da produtividade. As tentativas de intervenção profissional qualificada em esporte coletivos como voleibol e basquetebol dependem de mudanças na estrutura e organização pedagógica ( GALATTI; PAES, 2003; SOUZA, 1999) Por outro lado os esforços das teorias críticas não obtiveram conexão com os determinantes das práticas esportivas coletivas.

\section{OBJETIVOS}

- Discutir o conceito de educação esportiva em jogos e competições.

- Mapear aspectos gerais e específicos da Pedagogia do esporte.

- Apresentar uma proposta metodológica.

\section{METODOLOGIA}

-Levantamento bibliográfico e seleção de referências nacionais.

- Tradução do livro "Sport foundations for elementary physical education" (MITCHELL; OSLIN; GRIFFIN, 2003).

- Esboço de proposta de intervenção.

- Redação do artigo. 


\section{CONTRIBUIÇÕES GERAIS DA PEDAGOGIA DO ESPORTE}

Dentro da área de educação física, os conhecimentos relativos ao ensino dos esportes pertencem à pedagogia do esporte, que é uma subárea ou campo especificamente responsável pelo desenvolvimento de metodologias adequadas para atividades individuais e/ou coletivas, cujo tratamento didáticoesportivo é baseado no ensino de táticas e técnicas por meio de jogos. Este setor, embora ainda embrionário na grande área, tem sido denominado de pedagogia do esporte ou esporte escolar.

A lógica esportiva baseada na repetição e imitação de movimentos deve ser re-significada aumentando a possibilidade de escolhas que são sementes do desenvolvimento da autonomia e inteligência social no jogo. O professor que provocar um ensino crítico-propostivo, inovador, construtivo e diretivo passa a ser um elo de ligação (meio) entre a aprendizagem do aluno e o conhecimento, não simplesmente, o fim do conhecimento (SADI, 2004).

Nesse sentido o ensino de esportes por meio de jogos, deve ser tratado no âmbito escolar com a perspectiva de desenvolvimento integral.

A formação da cidadania, da responsabilidade, da autonomia e da independência baseada nas atividades de estímulo à consciência crítica e inteligência nos jogos deve ser (re)significada. Problemas simples são indicados às crianças menores e problemas de e maior complexidade aos adolescentes e jovens. (...) Paralelamente ao ensino da leitura, da escrita, da matemática, a educação esportiva deve ocupar um lugar de destaque na formação da inteligência/ pensamento estratégico (...) também a busca por autonomia e desenvolvimento da inteligência, da capacidade de detectar e solucionar problemas deve ser um dos principais objetivos dos planejamentos e projetos pedagógicos. (SADI, 2004).

Observamos que se torna impossível o ensino de todos os esportes, por vários motivos (materiais, estrutura física e tempo concreto e pedagógico) e, por isso, a prioridade àqueles que participam ativamente do cotidiano social, cultural e histórico, estando disponíveis para a aprendizagem. Todavia, não podemos negar ou omitir o conteúdo de vários outros esportes, sua contextualização e discussão. No ensino desta cultura esportiva deve ser levada em consideração uma visão de educação espiralada na qual o conhecimento é revisto, reaprendido e reelaborado. Não se trata, de apresentar o esporte como sinônimo de modalidades (partes), mas como totalidade inserida socialmente.

Para nossos propósitos, o ensino do esporte escolar se processa nos procedimentos metodológicos do ensino por meio de jogos. Nas séries iniciais, principalmente, o universo lúdico e de fantasia permite tal 
conjugação. Mas para isso é necessário à pedagogia do esporte Cultivar um modo de pensar e agir comprometido com a condição humana das pessoas. Isso não exclui desenvolver as capacidades e ensinar as habilidades. Vai além: a tarefa da pedagogia é a de favorecer o bem-estar das pessoas e sua vida social. Aprender esporte, seja qual for, é bom quando os conteúdos propostos em uma aula, independentemente do cenário se generalizem para a vida. (SANTANA, 2005).

A pedagogia do esporte, abordada neste texto, agrega jogos, festivais, brincadeiras, ludicidade, além do ensino de técnicas e táticas. Agregar essas manifestações da cultura ao esporte, tanto pode ser feita do ponto de vista de preparar para o esporte, como de viver a realidade da infância e da adolescência no esporte. A compreensão do esporte de forma ampla, organizando-o não apenas por meio de técnicas corporais, mas também da imaginação, inteligência tática, atividades de cooperação e conhecimento do esporte pode ser mais inclusiva do que se imagina. Com a promoção de competições no sentido da inclusão (social e pedagógica), podemos caminhar para a democratização e massificação do esporte.

Ao levar os alunos a compreender a lógica do jogo, criando oportunidades de desenvolvimento da inteligência individual e coletiva, integrando a comunidade com a escola no estímulo, preparação e avaliação dos jogos, estaremos reorientando os significados do esporte. Isso pode ser feito desde a infância até a adolescência, de forma seqüencial e por meio de adequações nas faixas etárias (por exemplo, 7 e 8 anos, 9 e 10, etc.).

\section{CONTRIBUIÇÕES ESPECÍFICAS DA PEDAGOGIA DO ESPORTE}

Apresentamos na seqüência uma síntese da proposta americana relativa à organização/sistematização das aulas de esporte. $\mathrm{O}$ ensino de esportes para crianças dentro da pedagogia do esporte ainda é pouco explorado no Brasil. No estudo realizado verificamos que a eficácia no tratamento organizacional da educação física e esporte é ditada pela dinâmica curricular e a abordagem metodológica baseada na compreensão do jogo. Tal eficácia pode ser comprovada na abrangência de procedimentos que vão dos mais simples aos mais complexos, via de regra, da idéia mais geral ao fazer/executar específico, sempre contemplando múltiplas dimensões.

O esporte, como herdeiro do jogo, possui dois pontos relevantes para o ensino/aprendizagem: a estruturação de jogos e a promoção/substituição das tradicionais modalidades esportivas por atividades em jogos esportivos. 
A classificação dos esportes envolve quatro categorias de jogos: jogos de invasão, jogos de rede/parede, jogos de rebatida/campo e jogos de alvo. Neste texto a ênfase da análise de ensino de esporte por meio de jogos será relativa à organização/sistematização das aulas de esporte.

O conhecimento em esportes deve inicialmente ser adaptado/ajustado às características das crianças jogadores, que podem facilmente reproduzir diferentes jogos retendo um grau de conhecimento dos processos ou técnicas de jogo, transferidos de um para outro - o que justifica a utilização de espaços reduzidos. Além dos mini-jogos a referida metodologia discute as dimensões de quadras, a necessária diminuição do número de jogadores, o peso de bolas bem como os tamanhos/alturas de equipamentos e tempos de jogo.

O conceito de jogos esportivos substitui o termo modalidades, pelo sentido plural que os esportes carregam em sua densidade qualitativamente diferente das modalidades esportivas que enfatizam uma conotação no singular. Em outras palavras, o universo de práticas esportivas é constituído por jogos de diferentes famílias, formadoras de vários tipos de comunidades.

Os jogos mais simples devem ser ensinados em seqüências apropriadas e relacionadas com a possibilidade de totalidade. Classificados mediante as questões táticas e a solução de problemas, o ensino dos jogos se constitui por uma tríade interativa, composta por: 1) Decisões a serem realizadas; 2) Movimento sem bola; 3) Seleção e execução de habilidades com bola.

A proposta utiliza jogos modificados, permitindo maior flexibilização para a seleção e seqüência de conteúdos. Além disso, possibilita a transferência de táticas e habilidades entre os jogos e permite aos alunos diversificar sua experiência, antes das práticas específicas de habilidades.

Para cada categoria de jogo, três níveis de unidades contendo uma série de planos de aula são desenvolvidos na dinâmica curricular. Cada aula indica ao professor a dosagem, flexibilização e adaptação nos conhecimentos esportivos e inclui:

- Um problema tático;

- Um foco da aula;

- Objetivos;

- Jogos; 
- Tarefas práticas;

- Perguntas e respostas em forma de avaliação.

A educação esportiva a partir desta proposta metodológica deve ser flexível suficiente para abarcar a diversidade de conteúdos existentes na cultura esportiva. $\mathrm{O}$ engajamento dos estudantes, a estrutura educacional e a organização pedagógica também constituem fator imprescindível para o alcance da qualidade no esporte.

Nesse sentido a articulação teórico-prática da pedagogia do esporte (contribuições gerais e específicas) possibilita a construção de projetos, planos e novos horizontes para os professores de Educação física.

Proposta de jogos e competições: testando uma educação esportiva

Festivais Esportivos podem ser traduzidos por eventos em que o esporte é tratado a partir de uma ênfase festiva e de integração da comunidade ao esporte-lazer. O caráter lúdico de participação de pais e alunos é uma característica marcante. Já Competições Pedagógicas são eventos mais elaborados, organizados a partir de formas refinadas de tratamento do esporte escolar/educacional. Com regulamentos adaptados e específicos, visando o bem-estar-social dos praticantes bem como o conhecimento crítico-criativo, estas competições podem ser exploradas em variados aspectos, desde a preparação, passando pela arbitragem e chegando à avaliação participativa. Tanto teoricamente quanto do ponto de vista da aplicação, os estudantes são levados a uma ação e reflexão do esporte. Para alcançar os objetivos propostos preferimos não utilizar o conceito de Festivais Esportivos. Desta forma as competições aqui propostas devem se orientar pelas seguintes diretrizes pedagógicas:

- Organização do registro e a anotação das partidas;

- Socialização de regras antes do início efetivo das competições - Realizar jogos de "aquecimento" para familiarizar os jogadores (jogos "sem valor"/jogos de "preparação");

- Estímulo à criação de táticas de jogo;

- Construção de planilhas de observação tanto para os jogos de 06 por equipe como para os mini jogos $(3 \times 3)$

- Registro de Fotos e coleta de dados dos jogadores

- Interação em ambientes virtuais como Blog

- Avaliação dos resultados: apresentação em forma de pôster (relatório final) O envolvimento de professores e alunos nas competições pode estimular reflexões sobre o fazer esportivo e, 
dessa forma, articular as principais tarefas relativas à (1) organização, (2) aplicação e (3) avaliação dos eventos. Isso implica no planejamento do seguinte calendário:

a) Elaboração conjunta e democrática do calendário, atividades, equipes, jogos, responsabilidades e direitos dos envolvidos. Um "contrato coletivo" pode ser objeto de discussão, votação e divulgação. No final, também pode ser assinado por todos.

b) Criação de um sistema de disputa no qual os jogos são sempre precedidos de uma atividade preparatória, isto é, um jogo educativo no qual são apresentados os princípios éticos, a arbitragem pedagógica e as regras da competição. Durante este movimento, alunos que não participam diretamente do jogo poderão registrar as atitudes e os principais fatos ocorridos na partida.

c) A avaliação de cada jogo deve ser motivo de aprendizagem coletiva. Os grupos são reunidos em círculo e há uma conversa sobre os principais fatos ocorridos na partida, registrados pelos alunos que não estavam participando diretamente do jogo. Esta conversa é registrada em uma ata do jogo. Um relatório final pode ser elaborado pelo professor e socializado entre todos os alunos.

Outra questão importante é a forma de premiar os alunos. Por exemplo, as medalhas podem ser substituídas por troféus (coletivo) e por certificados de mérito (individual). Isso contribui para a atenuação da premiação de primeiro, segundo e terceiro lugares (por destaques), valorizando, assim, a participação e democratizando as competições e festivais. Os prêmios são estímulos e incentivos para os alunos destacados e também podem ser agregados a todos os participantes.

A condução de todo o processo de competição deve ser feita pelo professor. Em outras palavras, se não houver tal condução, tampouco haverá o interesse dos alunos. Uma breve discussão dos resultados e significados das competições deve ser um elemento central de debate franco e aberto, pois isso indica a importância do processo estimulando a participação e reflexão dos alunos.

\section{CONSIDERAÇÕES FINAIS}

Para os limites deste artigo entendemos que as noções de totalidade e cultura devem ser problematizadas na articulação com as práticas pedagógicas Esboçamos uma fundamentação para a pedagogia do 
esporte buscando relacionar temas do debate acadêmico com a realidade da Educação Física.

O jogo esportivo como conceito recuperado a partir da citada teoria americana apresenta-se potencialmente como o meio mais eficaz de ensino-aprendizagem de esportes. Situado na tensão entre a educação tradicional/tecnicista e a perspectiva construtivista/sócio-interacionista, para os efeitos desta proposta, este conceito integra as qualidades destas duas lógicas, visando promover sua superação.

Aproximamos a pedagogia do esporte ao eixo das ciências humanas discutindo o processo do saber esportivo a partir de determinantes culturais e de educação global. Dentro destes aportes entendemos que os caminhos e práticas pedagógicas necessitam ser qualificados e re-significados. Isso requer uma recuperação da pedagogia do esporte como subárea da Educação Física e, ao mesmo tempo, um esforço de elaboração crítica, de cunho teórico e prático que avance na construção de alternativas viáveis e possíveis para a realidade brasileira.

Eventos esportivos são momentos importantes para qualificar tal articulação. Indicam experiências a serem registradas e possibilidades de inovação. Nesse sentido o tema da educação esportiva por meio de jogos exige uma participação integrada de professores, alunos e comunidade escolar. Quando articulados com um planejamento integrado e democrático de aulas, os eventos esportivos podem se tornar motivantes e atrair o interesse para a prática e o conhecimento dos esportes.

Na mesma direção a dinâmica curricular deve ser alterada com a inclusão de aulas de esporte escolar. A quantidade de aulas (número de aulas semanais de Educação física -componente curricular somada à Educação esportiva ou Esporte Escolar - complemento do currículo) deve ser combinada com a qualidade que apresentamos, isto é, incrementos na estrutura física dos locais, material pedagógico novo e durável, além das questões organizativas, pedagógicas e metodológicas. Isso pode, no espaço de médio prazo, indicar melhorias e mudanças para todos os envolvidos.

O esporte como elemento agregador de cultura e educação não deve pois se furtar ao compromisso e ao desafio desta nova possibilidade. Entre as considerações teóricas da atualidade, as contribuições de MITCHELL, S. A; GRIFFIN, L. L, OSLIN, J. L. (1997, 2003) podem ser bem aproveitadas pelos brasileiros.

Por fim, consideramos que a abordagem de ensino de esporte por meio de jogos necessita ser testada e experimentada antes de aprovada. As Universidades e instituições de ensino básico podem aplicar projeto

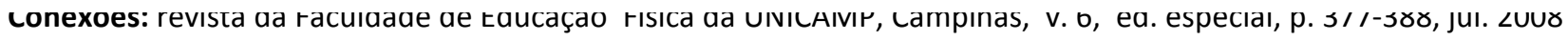
उठ0 ISSN: $1983-9030$ 
piloto para iniciar o trabalho. Nossa hipótese é de que tal abordagem será bem aceita, pois é orientada por uma perspectiva inclusiva e democrática, valores universalmente consolidados.

\section{REFERÊNCIAS}

ALBERTI, H.; ROTHENBERG, L. Ensino de jogos esportivos. São Paulo: Ao Livro Técnico, 1984.

DAOLIO, J. Educação Física e o conceito de cultura. Campinas: Autores Associados, 2004.

DIECKERT, J. Esporte de lazer: tarefa e chance para todos. São Paulo: Ao Livro Técnico, 1984.

DUCKER, L. C. B. Em busca da formação de indivíduos autônomos nas aulas de educação física. Campinas: Autores Associados, 2004.

FREIRE, J. B. Métodos de confinamento e engorda. In: MOREIRA, W. W. (Org.). Educação Física \& Esportes.

perspectivas para o século XXI. Campinas: Papirus, 1992.

. Pedagogia do futebol. Londrina: Midiograf, 1999.

FREITAS, L. C. de. Uma pós modernidade de libertação: reconstruindo as esperanças. Campinas: Autores Associados, 2005.

GALATTI, L. R.; PAES, R. Pedagogia do esporte: discutindo possibilidades de intervenção na modalidade basquetebol. Anais do XIII Congresso Brasileiro de Ciências do Esporte, Caxambu, 2003. MITCHELL, S. A, GRIFFIN, L. L, OSLIN, J. L. Teaching sport concepts and skill: a tactical games approach. Champaing: Human Kinetics, 1997.

. Sport Foundations for elementary Physical Education: a tactical games approach.

Champaing, Human Kinetics, 2003.

SADI, R. S. Pedagogia do esporte. Brasília: Ed. da UNB: MEC, 2004.

. Educação física, trabalho e profissão. Campinas: Komedi, 2005.

SANTANA, W. C. de. Pedagogia do esporte na infância e complexidade. In: PAES, R. R.; BALBINO, H. F. (Orgs.). Pedagogia do esporte: contextos e perspectivas. Rio de Janeiro: Guanabara Koogan, 2005. SILVA, T. T da. Documentos de identidade: uma introdução às teorias do currículo. Belo Horizonte: Autêntica, 2002.

SOUZA, A. J. É jogando que se aprende: o caso do voleibol. In: PICCOLO, V. L. N. Pedagogia dos esportes. Campinas: Papirus, 1999. 


\section{Renato Sampaio Sadi}

Faculdade de Educação Física - Universidade Federal de Goiás

Referência do artigo:

ABNT

SADI, R. S Temas da pedagogia do esporte, educação esportiva e competições. Conexões, v. 6, p. 377$388,2008$.

APA

Sadi, R. S. (2008). Temas da pedagogia do esporte, educação esportiva e competições. Conexões, 6, 377388.

\section{VANCOUVER}

Sadi, RS. Temas da pedagogia do esporte, educação esportiva e competições. Conexões, 2008; 6: 377388. 